IOSR Journal of Engineering

e-ISSN: 2250-3021, p-ISSN: 2278-8719,

Vol. 2, Issue 12 (Dec. 2012), ||V1|| PP 16-20

\title{
Vibration testing and controlling for wind turbine generator
}

\author{
Ling-Li Jiang ${ }^{1}$, Ping Li $^{1}$ Hua-Kui Yin ${ }^{1}$ Si-Wen Tang ${ }^{2}$ \\ ${ }^{1}$ (Hunan Provincial Key Laboratory of Health Maintenance for Mechanical Equipment, Hunan University of \\ Science and Technology, Xiangtan 411201, China) \\ ${ }^{2}$ (Engineering Research Center of Advanced Mining Equipment, Ministry of Education, Hunan University of \\ Science and Technology, Xiangtan 411201, China)
}

\begin{abstract}
Generator is the key composition of wind turbines. The vibration of generator would accelerate the wear of its parts and shorten the service life, at the same, the vibration are easy to evoke the vibation of neighbor devices that would make lots of noise, so the study on the techonology of vibration testing and controlling for generator has important significance to the safe and efficient operation of generator, even wind turbines. This paper performs vibration testing on three over-vibration generator, and the collected vibration signals are analyzed, the causes of the over-vibration are illustrated, then the actions of vibration controlling are adopted, finally, the over-vibration are controlled efficiently. This studies has instructional significance and referenced value for the over-vibration adjustment and controlling in the running scene.
\end{abstract}

Keywords:- Wind turbine generator, vibration testing, signal process, vibration controlling

\section{INTRODUCTION}

Over the past decade, continually growing energy demands as well as global warming and other pollution concerns have drawn considerable attention to the need for alternative, free, and renewable source of energy — wind energy[1]. Wind energy is one of the most attractive sources of renewable energy. During the last decade, wind turbines were extensive application through the world. There are 3.580 million KW new wind turbines。In 2010, the world's new wind power installed capacity is up to 35.8 million kilowatts and the total of wind power installed capacity is up to 194.4 , which is an increase of $22.5 \%$ over 2009.[2-3] The wind turbine is constituted by the wind wheel, pitch system, wheel hub, body (including the cabin, base and tower), transmission actuator, gearbox, generator, controll system, sensors, break system, hydraulic system, yaw-control system, and so on.[4-5] By the wind turbine, the wind energy is transformed into mechanical energy firstly, and then drawing support from the main shaft, gearbox, and generator, the mechanical energy is transformed into electrical energy that achieve the wind power generation. The generator is the key composition of wind turbines. [6] It is responsible for the rotational mechanical energy conversion to the elctrical enegy and power supply for the electrical system. The generator vibration will accelerate the motor bearing wear, so that the normal service life of the bearings are greatly reduced. Due to the motor vibration could easily lead to the end winding mutual friction, the insulation is reduced and the insulation life is shortened. At the same, the vibration are easy to evoke the vibation of neighbor devices that would make lots of noise. Prolonged vibration motor is apt to cause bearing hugging, the rotor shaft damage, even the sweep clean damage, which would be serious damage to the motor and greatly increasing the maintenance costs. Generator vibration is related to many factors, such as operation mode, grease, manufacturing quality, so there are many factors should be considered when diagnosis of the cause of generator vibration, which put forward higher requirements to the technology workers. [7-8] This paper performs vibration testing on three over-vibration generator, and the collected vibration signals are analyzed, the causes of the over-vibration are illustrated, then the actions of vibration controlling are adopted, finally, the over-vibration are controlled efficiently.

\section{VIBRATION TESTING}

The acceleration signals near the bearing of the generator are collection as the measurement magnitudes. The root-mean-square (RMS) values of the acceleration signal are calculated as the standard to verify if existing over-vibration. The equation of the root-mean-square value is shown as follows:

$$
x_{r, m, s}=\sqrt{\frac{1}{2}\left(x_{\max }^{2}+x_{\max }^{2}\right)}
$$


where $x_{\max }$ is the maximum RMS and $x_{\min }$ is the minimum RMS.

Acceleration signals were collected using the Dewetron 16 channels data acquisition system and IMI 608A11 accelerometers. The scope of the frequency response is from $3 \mathrm{~Hz}$ to $10 \mathrm{KHz}$. A hand-held vibration meter is also used for measuring the RMS of acceleration signal directly.

The tested motor is mounted directly on the hard basis, rigid and horizontal installation. The following condition is ensured that the maximum vibration acceleration in two horizontal and vertical directions of the motor bottom feet do not exceed the $25 \%$ of the maximum vibration acceleration near the bearing.

The simple structure of the generator is shown in figure 1. It can be found the generator include a drive end and a non drive end. The acceleration sensors installation point layout is shown in figure 2 . The generator is in the empty state during vibration testing. The rated speed is $1800 \mathrm{rpm}$. The acceleration vibration signals of two steady state --rotating speed with 900rpm and $1800 \mathrm{rpm}$ of three generators are measured.

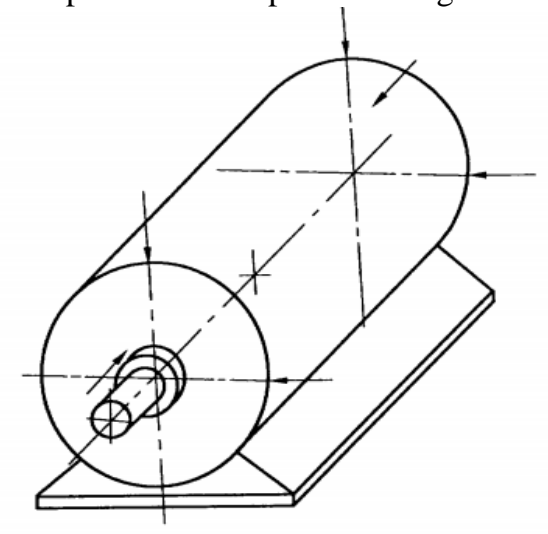

Fig.1 The simple structure diagram of the generator

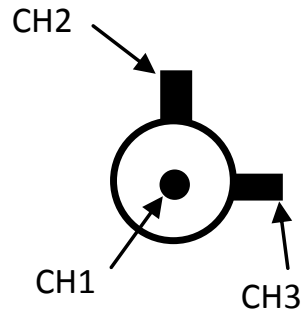

a) The drive end

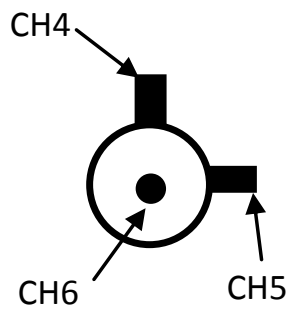

b) The non drive end

Fig. 2 The testing point layout

\section{ANALYSIS OF CAUSES AND SOLUTION}

The RMS of the accelerations by using the hand-held vibration meter are shown in table 1. In order to distinguish the data after taking the vibration controlling actions, the testing is defined as the first state, corresponding, the testing after taking the vibration controlling actions is regarded as the second state. It can be found from table 1 that there are over-vibration phenomenon in all the three tested generators, because parts of RMS is over $2.8 \mathrm{~m} / \mathrm{s}^{2}$ while the relevant ISO criterion provided all the RMS must be below $2.8 \mathrm{~m} / \mathrm{s}^{2}$.

Table 1 The RMS of the accelerations by using the hand-held vibration meter in the first state

\begin{tabular}{|c|c|c|c|c|c|}
\hline \multirow{4}{*}{$\begin{array}{c}\text { Number of } \\
\text { Generator }\end{array}$} & $\begin{array}{c}\text { Rotating } \\
\text { speed }\end{array}$ & $\begin{array}{c}\text { The position } \\
\text { of the sensor }\end{array}$ & $\begin{array}{c}\text { Radial } \\
\text { direction }\end{array}$ & $\begin{array}{c}\text { Axial } \\
\text { direction }\end{array}$ & $\begin{array}{c}\text { Vertical } \\
\text { direction }\end{array}$ \\
\hline \multirow{3}{*}{1} & \multirow{2}{*}{$1750 \mathrm{rpm}$} & Drive end & 2.9 & 1.6 & 0.6 \\
\cline { 3 - 6 } & \multirow{2}{*}{$900 \mathrm{rpm}$} & Non drive end & 3.9 & 3.7 & 4.8 \\
\cline { 2 - 6 } & & Drive end & 2.4 & 3.2 & 3.6 \\
\cline { 2 - 6 } & & Non drive end & 7.4 & 3.6 & 6.2 \\
\hline
\end{tabular}




\begin{tabular}{|c|c|c|c|c|c|}
\hline \multirow{3}{*}{2} & \multirow{3}{*}{$1750 \mathrm{rpm}$} & Drive end & 0.4 & 0.4 & 0.5 \\
\cline { 3 - 6 } & & Non drive end & 1.0 & 0.8 & 0.8 \\
\cline { 3 - 6 } & \multirow{3}{*}{$900 \mathrm{rpm}$} & Drive end & 1.6 & 0.5 & 5.0 \\
\cline { 3 - 6 } & \multirow{3}{*}{$1750 \mathrm{rpm}$} & Non drive end & 0.5 & 0.7 & 0.4 \\
\hline \multirow{3}{*}{3} & \multirow{3}{*}{$900 \mathrm{rpm}$} & Drive end & 1.2 & 2.9 & 1.6 \\
\cline { 3 - 6 } & & Non drive end & 4.3 & 2.1 & 5.0 \\
\cline { 3 - 6 } & & Drive end & 2.1 & 0.3 & 2.6 \\
\cline { 3 - 6 } & & Non drive end & 1.2 & 0.5 & 2.7 \\
\hline
\end{tabular}

In order to find out the causes of the over-vibration, the acceleration signals tested by the Dewetron data acquisition system are analyzed. Figure 3 Figure 5 are the typical time domain and frequency domain atlas of the three tested generator with the rotating speed near 1800rpm.
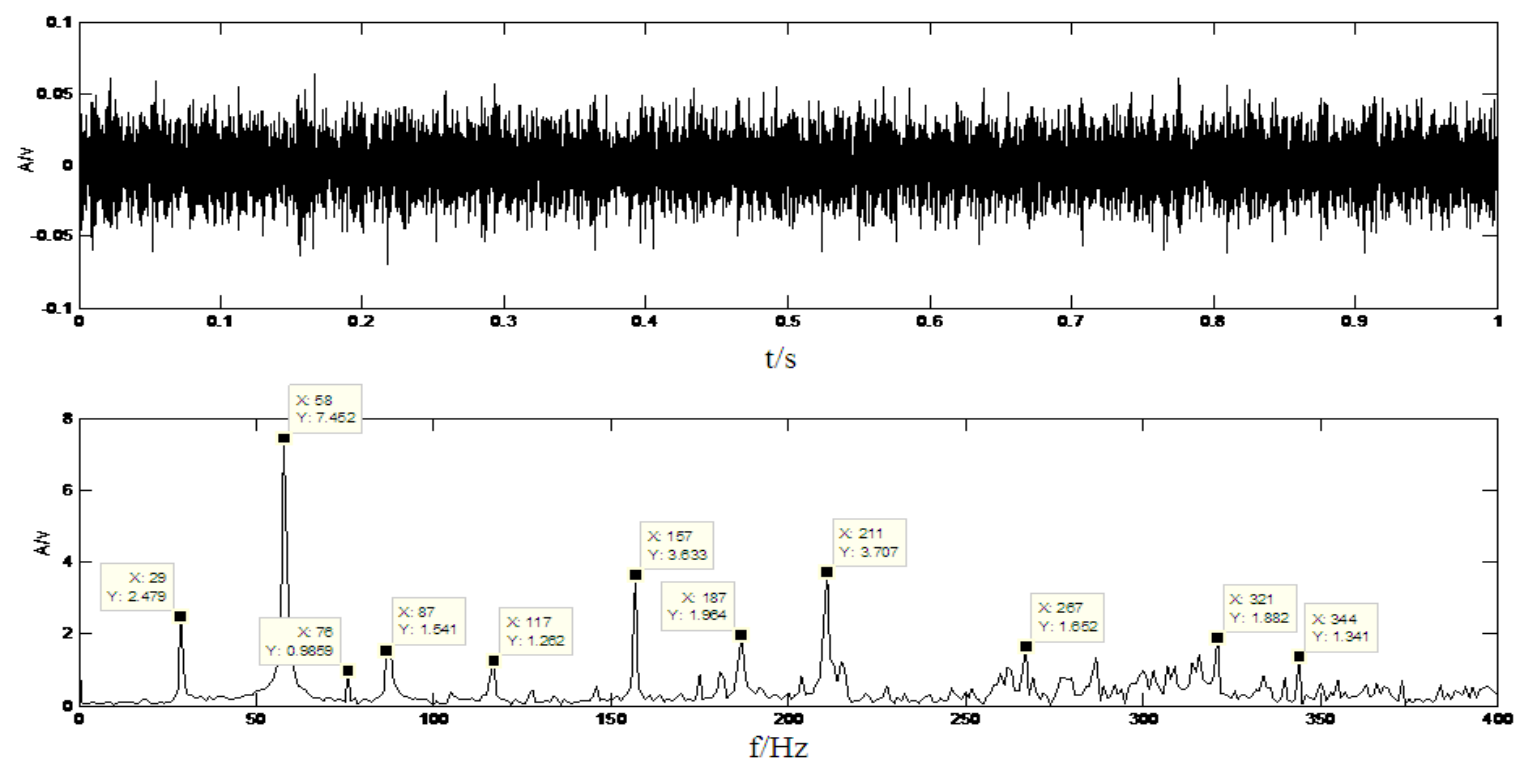

Fig. 3 The typical signal in time and frequency domain of the first generator
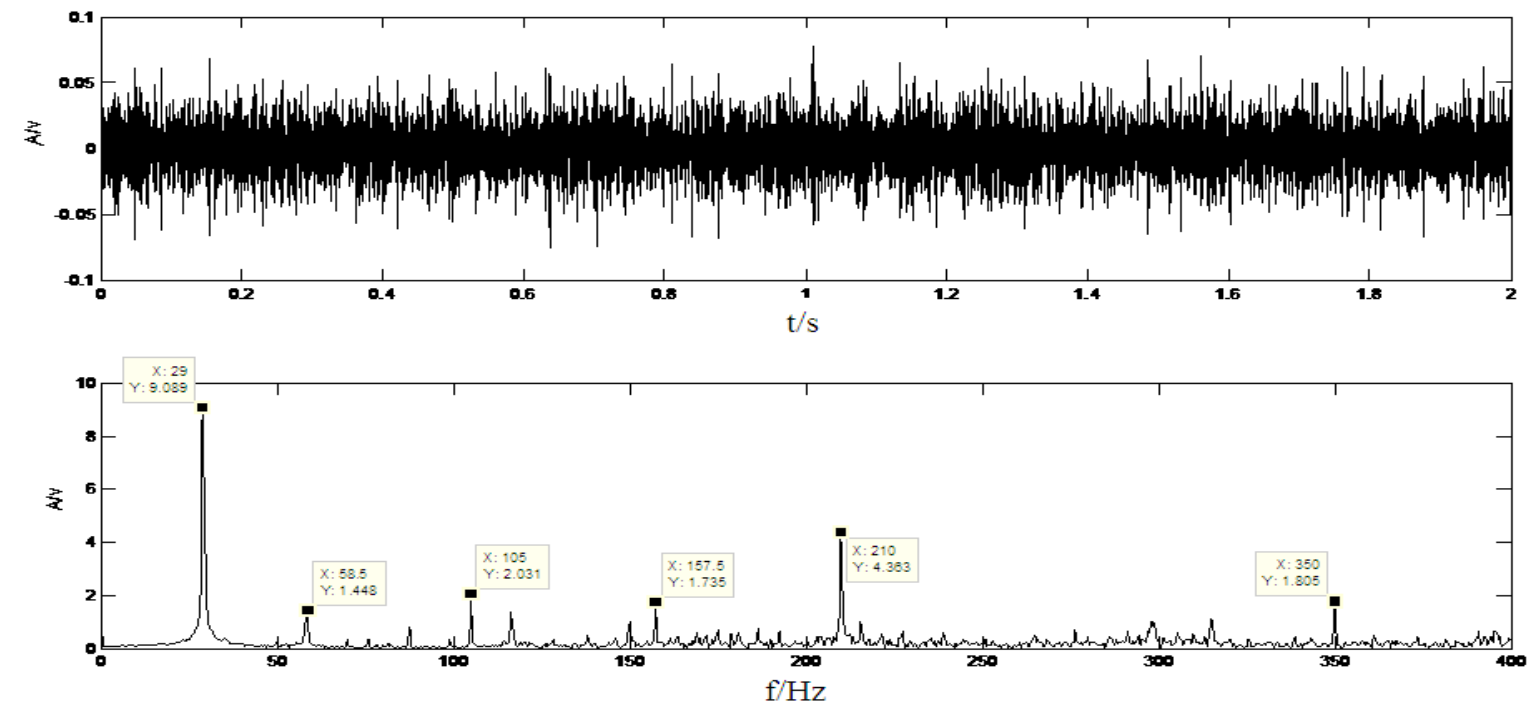

Fig. 4 The typical signal in time and frequency domain of the second generator 

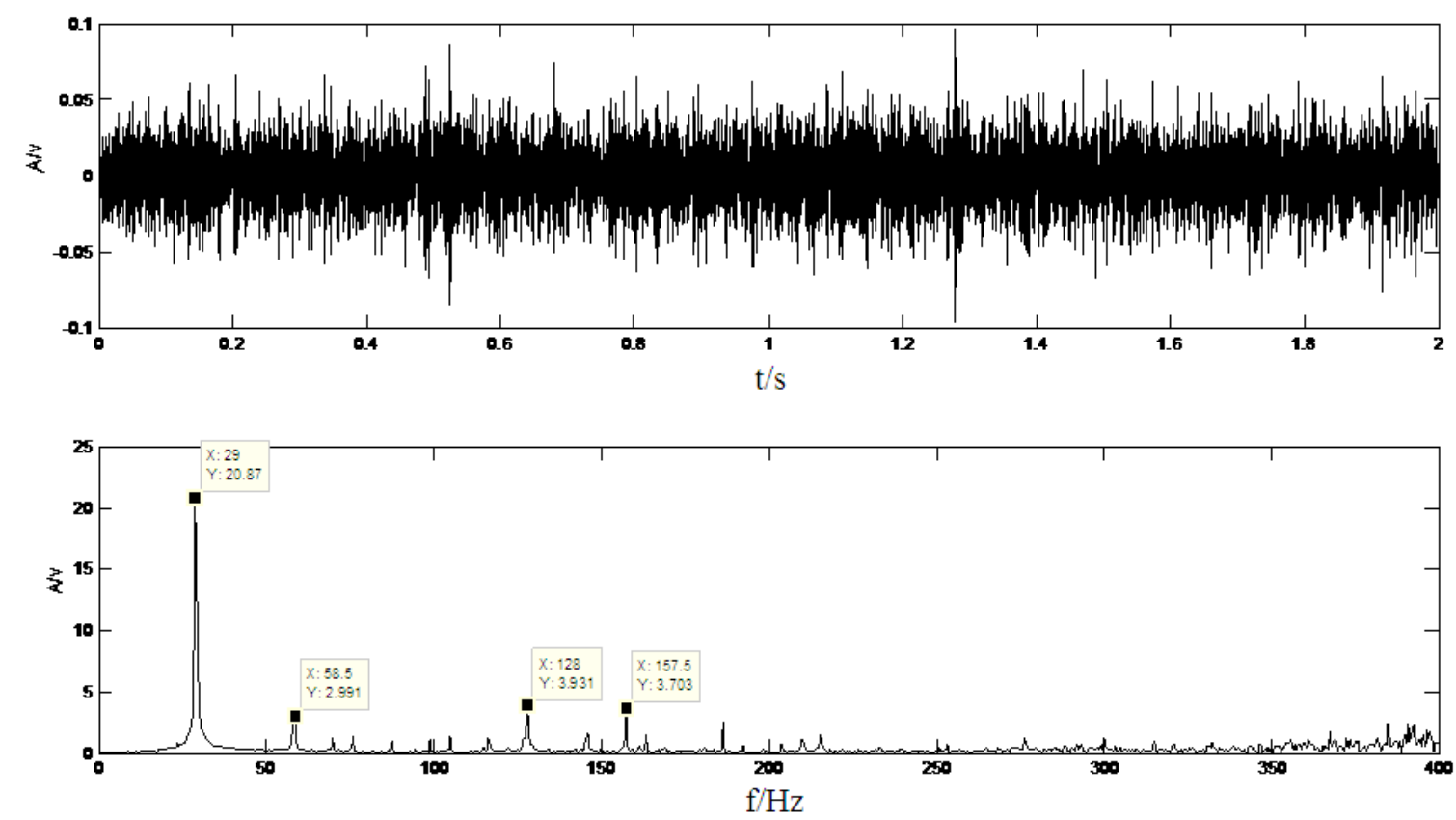

Fig. 5 The typical signal in time and frequency domain of the third generator

It can be found from figure 3 that the second rotating frequency is outstanding and there are seriers of disperse frequency.The second rotating frequency meas there exist imbalance rotor damage and the disperse frequency means there exist bearing damage in the first generator. It can be found from figure 4 and figure 5 that the first rotating frequency is outstanding, which means there exsits misalignment damage. The corresponding actions are taken for controlling the over-vibaration. Dynamic balance adjustment and bearing clearance adjustment are executed in the first generator and laser alignment adjustment is executed in the second and third generator. The RMS of acceleration is measured by using the hand-held vibration meter after adjusted. The measurement results are shown in Table 2. It can be found from table 2 that the vales of RMS are all below $2.8 \mathrm{~m} / \mathrm{s}^{2}$. The over-vibrations are controlled effectively.

Table 2 The RMS of the accelerations by using the hand-held vibration meter in the second state (after taking

\begin{tabular}{|c|c|c|c|c|c|}
\hline $\begin{array}{l}\text { Number of } \\
\text { Generator }\end{array}$ & $\begin{array}{c}\text { Rotating } \\
\text { speed }\end{array}$ & $\begin{array}{l}\text { The position } \\
\text { of the sensor }\end{array}$ & $\begin{array}{c}\text { Radial } \\
\text { direction }\end{array}$ & $\begin{array}{c}\text { Axial } \\
\text { direction }\end{array}$ & $\begin{array}{r}\text { Vertical } \\
\text { direction } \\
\end{array}$ \\
\hline \multirow{4}{*}{1} & \multirow{2}{*}{ 1750rpm } & Drive end & 2.6 & 1.4 & 0.8 \\
\hline & & Non drive end & 2.7 & 1.7 & 1.2 \\
\hline & \multirow{2}{*}{ 900rpm } & Drive end & 2.4 & 1.9 & 2.6 \\
\hline & & Non drive end & 7.4 & 3.6 & 6.2 \\
\hline \multirow{4}{*}{2} & \multirow{2}{*}{$1750 \mathrm{rpm}$} & Drive end & 0.5 & 0.8 & 1.5 \\
\hline & & Non drive end & 1.6 & 1.2 & 1.2 \\
\hline & \multirow{2}{*}{ 900rpm } & Drive end & 1.6 & 1.8 & 2.6 \\
\hline & & Non drive end & 0.5 & 0.7 & 0.4 \\
\hline \multirow{4}{*}{3} & \multirow{2}{*}{$1750 \mathrm{rpm}$} & Drive end & 1.2 & 2.4 & 1.6 \\
\hline & & Non drive end & 2.8 & 2.1 & 2.4 \\
\hline & \multirow{2}{*}{ 900rpm } & Drive end & 2.1 & 0.3 & 2.5 \\
\hline & & Non drive end & 1.8 & 0.6 & 2.5 \\
\hline
\end{tabular}




\section{CONCLUSION}

Study on the techonology of vibration testing and controlling for generator has important significance to the safe and efficient operation of generator, even wind turbines. This paper performs vibration testing on three over-vibration generator, and the collected vibration signals are analyzed, the causes of the over-vibration are illustrated, then the actions of vibration controlling are adopted, finally, the over-vibration are controlled efficiently. This studies has instructional significance and referenced value for the over-vibration adjustment and controlling in the running scene.

\section{ACKNOWLEDGEMENTS}

This work is supported by the Hunan province science and technology plan projects (2011GK3161, 2012GK3100), the scientific research fund of Hunan provincial education department(11A034) and the aid program for science and technology innovative research team in higher educational institutions of Hunan province.

\section{REFERENCES}

1) S.T. Wu, Three dimensional vibration generators with a single rotational input, Journal of Sound and Vibration, 330(4), 2011, 567-580.

2) V.G. Rau, G. Durga Prasad, Dynamic stability assessment of wind turbine generators using the Lyapunov function approach, Electric Power Systems Research, 27(1), 1993, ,61-72.

3) A.A. El-Sattar, N.H. Saad, and M.Z. Shams El-Dein, Dynamic response of doubly fed induction generator variable speed wind turbine under fault, Electric Power Systems Research, 78(7),2008, 1240-1246.

4) H. Li, B. Zhao, C. Yang, H.W. Chen,and Z. Chen, Analysis and estimation of transient stability for a grid-connected wind turbine with induction generator, Renewable Energy, 36(5),2011, 1469-1476.

5) E.A. Ogbonnaya, H.U. Ugwu, and K. Theophilus-Johnson, Gas Turbine Engine Anomaly Detection Through Computer Simulation Technique of Statistical Correlation, IOSR Journal of Engineering, 2(4), 544-554.

6) K. Yamamoto, T. Noda, S. Yokoyama, and A. Ametani, Experimental and analytical studies of lightning overvoltages in wind turbine generator systems, Electric Power Systems Research, 79(3),2009,436-442.

7) Y. Amirat, M.E.H. Benbouzid, E. Al-Ahmar, B. Bensaker, and S. Turri A brief status on condition monitoring and fault diagnosis in wind energy conversion systems, Renewable and Sustainable Energy Reviews, 13(9),2009,2629-2636.

8) Kathryn E. Johnson, and Paul A. Fleming, Development, implementation, and testing of fault detection strategies on the National Wind Technology Center's controls advanced research turbines, Mechatronics, 21(4), 2011,728-736. 